$\widetilde{G}_{\text {https://doi.org/10.3765/sp.12.20 }}^{\text {Semantics \& Pragmatics Volume 12, Article 20, } 2019}$

This is an EARLY ACCESS version of

Fusco, Melissa. 2019. Sluicing on free choice. Semantics and Pragmatics 12(20). 1-20. https://doi.org/10.3765/sp.12.20.

This version will be replaced with the final typeset version in due course. Note that page numbers will change, so cite with caution. 
EARLY ACCESS

\title{
Sluicing on free choice*
}

\author{
Melissa Fusco \\ Columbia University
}

\begin{abstract}
I explore the implications of the Tense Phrase deletion operation known as sluicing (Ross 1969) for the semantic and pragmatic literature on the Free Choice effect (Kamp 1973, von Wright 1969). I argue that the time-honored 'I don't know which'-riders on Free Choice sentences, traditionally taken to show that the effect is pragmatic, are sensitive to scope. Careful attention to such riders suggests that these sluices do not show cancellation on Free Choice antecedents in which disjunction scopes narrower than the modal.
\end{abstract}

\section{Introduction}

My purpose in this note is to explore the implications of the Tense Phrase ellipsis operation known as sluicing (Ross 1969) for the semantic and pragmatic literature on the so-called Free Choice effect (Kamp 1973, von Wright 1969) — or "FC" for short. FC is the phenomenon whereby a modalized sentence like

(1) You may have coffee or tea.

$\diamond$ (you have coffee or you have tea)

is interpreted as entailing (or otherwise communicating)

(2) You may have coffee and you may have tea. $(\diamond$ you have coffee $) \wedge(\diamond$ you have tea $)$

... a transition which is surprising because it is not valid in any normal modal logic. Note that, in setting out FC in this way, I assume that 'or' scopes below 'may' on the Free Choice interpretation of (1). While there is no consensus on this in the literature, it is a mainstream assumption.

Since Kamp's time, semanticists have argued that the felt entailment of (2) by (1) is cancellable - thus prima facie a pragmatic, rather than semantic, phenomenon. ${ }^{1}$ One such argument is made by appeal to constructions like (3):

* Warm thanks to Maria Aloni, Chris Barker, Matt Barros, Jennifer Carr, Hans Kamp, Josh Dever, Mario Guenther, Peter Jenks, Line Mikkelsen, Rachel Rudolph, Mandy Simons, Will Starr, Gary Thoms, Katja Vogt, Malte Willer, and to the editors and two anonymous referees at Semantics and Pragmatics.

1 It has been suggested to me that the term "cancellation" is no longer current in the linguistics literature for the effect of, e.g., (3b) on (3a). However, it has wide currency in philosophy (probably 
(3) a. You may have coffee or tea...

b. but I don't know which.

The discourse in (3) is clearly not felt to communicate $(2) .^{2}$ The claim that both coffee and tea are permitted is, on the contrary, in clear Moorean tension with (3), since (3b) features the speaker's subsequent declaration of ignorance regarding what is permitted. Call this the cancellation argument. The cancellation argument appears to show that FC is pragmatic, rather than semantic.

(3b) is a sluice: a deleted Tense Phrase under the wh-word 'which', comparable to the wh-word 'who(m)' in (4) and the wh-phrase 'which cat' in (5):

(4) a. She needed to talk to someone,

b. but they couldn't figure out $\left[[\mathrm{who}(\mathrm{m})]_{1}\right.$ [she needed to talk to $\left.\left.t_{\mathrm{T}}\right]\right]$.

a. Lola adopted a cat at the shelter,

b. but I don't know [[which eat $]_{1}$ [Lola adopted $\left.t_{\mathrm{T}}\right]$. $^{3}$

Moreover, (3b) is a certain kind of sluice: what I will call an ignorance sluice. Other types of sluices, such as the indifference sluice (under 'doesn't matter' in (6a)) and the encouragement sluice (under 'free to choose' in (6b)), do not appear to cancel FC.

(6) You may have coffee or tea...

a. It doesn't matter which.

b. Feel free to choose which.

How does the nature of sluicing bear on the cancellation argument, resting as it does on (3b)? The position on FC I think is best supported by the literature is one I will call the No-Cancel-Narrow (or "NCN") thesis:

$(\mathrm{NCN})$ : If the Free Choice interpretation of 'You may $\phi$ or $\psi$ ' depends on 'may' scoping over 'or', then the apparent cancellation

due to an influential discussion of such an example by Grice (1978: 45)). For more recent uses of "cancellation", see Simons (2005) and Zimmermann (2000).

2 A locus classicus of this observation, as well as the hypothesis that it is due to scope, is Kamp (1978: 271-274).

3 In (5), why is 'cat', which is not part of the embedded TP, nonetheless elided? There is widespread agreement in the sluicing literature that the NP complement of 'which' in the fronted DP is capable of undergoing a separate process of ellipsis - NP ellipsis — when its content is recoverable from the context. Hence in (5) 'cat' is elided by a process that is distinct from sluicing, and operational in non-sluicing sentences like 'I saw Jessica's dog, and you saw Mike's.' (My reasons for nonetheless using the 'cat'-less version of (5) will become clear below.) 
Sluicing on free choice

induced by the sluice continuation 'But I don't know which' is not a pragmatic cancellation but a structural reinterpretation. This is because the sluice continuation 'I don't know which' is only compatible with 'or' scoping over 'may'. Hence, the scopally ambiguous antecedent $\ulcorner S$ may $\phi$ or $\psi\urcorner$ is being reinterpreted in the presence of the sluice as $\ulcorner(S$ may $\phi)$ or $(S$ may $\psi)\urcorner$.

In the context of Free Choice, the NCN has been suggested in previous work by Simons (2005) and Aloni (2007). If it is correct, then the cancellation argument does not go through.

I will sketch the case for the NCN as follows. In Section 2, I present two preliminary arguments. The first is a comparison between English disjunctive Free Choice sentences, like (1), and disjunctive Free Choice sentences in Tiwa (Tibeto-Burman), a language which appears to lexicalize disjunction scope. The second is a comparison between disjunctive ignorance sluices like (3b) and ignorance sluices licensed by indefinites in English and Italian. Neither of these preliminary arguments relies on a hypothesis about the internal structure of deleted tense phrases; rather, they show that where there is a lexical way to disambiguate scope, an analogue of the NCN appears to hold.

In Section 3, I do turn to claims about the internal structure of (3b). The NCN's reinterpretation claim depends on the hypothesis that 'may' is at-least-semantically present in the deleted material in (3b). I sketch the case for this - explaining what 'at-least-semantically present' means in the context of deletion - with the help of a naive argument from completion in Aloni (2019) and observations about parallelism of logical form between sluices and their antecedents in Chung et al. (1995).

Section 4 adds an argument for the overall picture - narrow-scope Free Choice 'or', wide-scope structural reinterpretation in (3b), and LF parallelism for ignorance sluices - on the basis of sluices with conjunctively interpreted antecedents. This combination of elements is situated to explain a novel observation about just which ignorance sluices are felt to trigger cancellation.

A survey of the literature, especially in philosophy, suggests that the NCN is not widely accepted by formal semanticists. Many authors hold that 'I don't know which'-sluices demonstrate cancellation while maintaining the mainstream assumption that disjunction scopes narrow at LF in Free-Choice triggering sentences (Kamp 1978, Zimmermann 2000, Starr 2016, Willer 2017). Others have embraced the less mainstream position that FC obtains for wide-scope 'or', but nontheless take the cancellation data to be relevant to it (Hawke \& Steinert-Threlkeld 
2015, 2016, Starr 2016, Willer 2017). ${ }^{4}$ Since the NCN holds that the LF targeted by the sluice cancellation is not the LF that gives rise to Free Choice, both types of position are in tension with the arguments to be put forth here.

\section{Free choice and the NCN: Preliminary evidence}

We begin with some cross-linguistic data from a language which lexicalizes disjunction scope. Tiwa (Tibeto-Burman), has two words, $b a$ and $k h i$, for disjunction. Dawson (2019) reports that it is only the narrow-scope-taking $b a$ and not the widescope-taking khí which gives rise to FC. Dawson explicitly rules out a semantically very similar rider to (3b) - viz., 'we can't remember which one it is' — on ba rather than khí. I report Dawson's data below.

(7) Saldi can drink tea or coffee.

a. Saldi [sa khí coffee] -go nung-a phon-o

Saldi tea or coffee -ACC drink-INF can-NEUT

$\checkmark$ Saldi is allowed to drink tea, but not coffee, (but we can't remember which one it is)

$\boldsymbol{x}$ Saldi is allowed to drink tea and she's allowed to drink coffee; it's her choice which.

b. Saldi [sa ba coffee] -go nung-a phon-o

Saldi tea or coffee -ACC drink-INF can-NEUT

$\boldsymbol{x}$ Saldi is allowed to drink tea, but not coffee, (but we can't remember which one it is)

$\checkmark$ Saldi is allowed to drink tea and she's allowed to drink coffee; it's her choice which.

(from Dawson 2019: 5, example (7))

Unlike Tiwa, English does not lexicalize the difference between wide- and narrow-scope disjunction. Hence an English sentence like

(8) Saldi may have coffee or tea.

4 It should be noted that Hawke \& Steinert-Threlkeld's papers focus on the case of epistemic modals, which may have special features w.r.t. cancellability: to wit, 'I don't know which'-sluices do not appear to cancel FC for epistemic modals. Pace Hawke \& Steinert-Threlkeld's dynamic-semantic account, however, this cancellability profile is consistent with the NCN; see, in particular, Zimmermann (2000), who offers a broadly Gricean account of Free Choice for wide-scope epistemic LFs, and notes that the "modal reduction principle" key to deriving the inference is plausible for epistemic modalities only (op. cit., 284). Hence if Zimmermann's account works, and the NCN correctly characterizes the landscape of Free Choice with regard to non-epistemic modalities, there is a threat that Hawke \& Steinert-Threlkeld's dynamic-semantic account is explanatorily redundant. 
Sluicing on free choice

a. $\searrow$ (Saldi has coffee or Saldi has tea)

b. $\diamond$ (Saldi has coffee $)$ or $\diamond($ Saldi has tea $)$

diamond, $\diamond$, appears twice - on either side of the disjunction - at LF.

According to the cancellation argument, the FC pattern $\diamond$ (Saldi has coffee or Saldi has tea $) \vDash \diamond$ (Saldi has coffee $) \wedge \diamond($ Saldi has tea $)$ is not semantic, because it can be cancelled by ignorance continuations like 'I don't know which'. But Dawson's data suggests that it is only (8b) that accepts such a continuation, while it is (8a) that gives rise to Free Choice in the first place. If this is correct, and the analogy between English and Tiwa holds, the cancellation argument misses its target. The interpreted LF of (3) (repeated):

(3) a. You may have coffee or tea...

b. but I don't know which.

is the analogue of (7a) with khí:

(9) a. $\nabla$ (you have coffee $)$ or $\diamond$ (you have tea $)$

b. but I don't know which.

The interpreted LF of (3a), (9a), is thus of a kind with sluices where the only significant scope-taking element is disjunction, as in

a. It's raining or it's snowing...

b. I don't know which.

The next argument relies on Free Choice sentences with indefinites. In combination with an ignorance sluice, these produce a pattern parallel to (3):

(11) a. You may sit in a chair.

b. (But) I don't know which.

When the 'a' in (11a) is replaced by the scope-sensitive English 'any' — indicating the indefinite takes narrow scope with respect to the modal - the discourse becomes noticeably degraded.

a. You may sit in any chair.

b. ? (But) I don't know which. 
This is noted, for example, in the widely-cited analysis of indefinite sluicing by Chung, Ladusaw, and McCloskey (1995; henceforth "CLM"). The suggestive a/any contrast in (11)-(12) recurs with scope-sensitive pronominal expressions in other languages, such as the Italian qualsiasi treated at length in Chierchia (2006) (I use Chierchia's suggested translation "whatever" for qualsiasi (op. cit., p. 540)):

a. $\varnothing \quad$ Puoi sederti in una sedia. $\varnothing .2 \mathrm{SG}$ may sit in a chair. You may sit in a chair.

b. $\mathrm{Ma} \varnothing$ non so quale. but $\varnothing .1 \mathrm{SG}$ not know.1SG which. but I don't know which.

(14) a. $\varnothing \quad$ Puoi sederti in qualsiasi sedia. $\varnothing .2 \mathrm{SG}$ may sit in whatever chair.

You may sit in whatever chair.

b. ? Ma $\varnothing$ non so quale.

? but $\varnothing .1 \mathrm{SG}$ not know.1SG which.

? but I don't know which.

Pairs like (11)-(12) and (13)-(14) motivate a single theoretical commitment, according to which the combination (narrow-scope indefinite + ignorance sluice) puts conflicting constraints on the scopal interpretation of $\exists$ and $\diamond$ in discourses like (12) and (14). This commitment can be framed in two ways: the first, SCOPE FACT (SF), is couched just in terms of the FC effect.

SCOPE FACT (SF). Indefinite Free Choice effects are most apparent in sentences where natural language indefinites scope under (rather than over) a modal diamond.

The second, IGNORANCE SLUICE OBSERVATION (ISO), highlights the consequences for the interpretation of 'but I don't know which':

IGNORANCE SLUICE OBSERVATION (ISO). Narrow-scope-taking indefinite FC sentences resist ignorance sluice cancellation.

If this is correct, then given the assumption that what logicians might call "existentials"that is, disjunction and indefinites-pattern alike, (11)-(14) constitute a second preliminary argument that the disjunction in (3) takes wide, rather than narrow, scope. 
Sluicing on free choice

It should be noted that this second argument-by-analogy assumes - following much, but not all, of the literature on 'any' in the wake of Kadmon \& Landman (1993) - that the so-called FCI 'any' (simply put, the any that gives rise to a Free Choice reading of (12a)) has the same narrow-scope-taking profile as the negative polarity 'any' in, for example, 'She didn't take any coffee'. ${ }^{5}$ However this claim has not gone unchallenged in the literature: for the case that FCI 'any', unlike NPI 'any', can outscope the modal operator, see Sæbø (2004) and Dayal (2004).

\section{Sluicing and structural interpretation}

In this section I argue 'may' is at-least-semantically present in the sluice (3b). This claim is important for establishing the NCN's thesis about the sluice's antecedent, the Free Choice sentence (3a).

A pair of sentences from Aloni (2019), which feature continuations more explicit than those under full sluicing, illustrate the importance of the claim. Aloni considers the pair (15)-(16):

(15) You may either eat the cake or the ice cream, I don't know which you may eat.

(16) You may either eat the cake or the ice cream, I don't care which you eat. (from Aloni 2019: 16, emphasis added)

An example from Meyer (t.a.) makes a comparable suggestion. Meyer considers the ignorance sluice (17b), to which she adds an explicit continuation with 'is allowed to':

a. John may eat an apple or a pear...

b. I don't know which.

= I don't know which one he is allowed to eat.

(Meyer t.a. p. 9; "=" notation in the original)

The 'don't know' continuations in (15) and (17), which appear to cancel the free choice effect, both feature a modal construction - 'may'/'is allowed to' - below the negated attitude verb. By contrast, the 'don't care' continuation in (16) does not

5 Indeed, given a view like CLM's, the oddity of the continuation (12b) provides evidence for this. Hence the point in (12) is parallel to the oddity of

(1) a. She didn't take any of the books.

b. ? (But) I don't know which.

See Chung et al. (1995: 255). 
feature the modal 'may'. This is important because the speaker seems to be saying, in the first case, that she doesn't know which of cake or ice cream the addressee may eat - her ignorance, in other words, concerns modality - but seems to be saying, in the second case, that she doesn't care which of cake or ice cream the addressee does eat - her indifference, in other words, concerns the actual world. The fact that 'which' takes different complements in the different sentences makes explicit that disjunction is interpreted above the world-shifting modal in (15) and (17), but below it in (16).

The NCN seeks to broaden this contrast between ignorance and indifference sluices to free choice antecedents like (18), where there is no verb like 'eat' in common between the two disjuncts:

(18) You may [[drink tea] or [eat cake]]...

a. I don't know which.

b. I don't care which.

These antecedents preclude continuations like Aloni's 'don't know which you may eat' and Meyer's 'don't know which one he is allowed to eat'. Instead, we find only disjunctive sluices. (18a) is, of course, an ignorance sluice on a Free Choice antecedent, just like (3b), and so falls under the scope of the pattern sketched by Aloni, Dawson, and Meyer.

The claim that 'may' is at-least-semantically present in ignorance sluices on free choice antecedents is the claim that an explicit version of (18a) - if such a thing were grammatically possible — would reveal an occurrence of the permission modal under 'don't know', just as Aloni's (15) features 'may' and Meyer's (17b) features 'is allowed to'. The corollary claim about FC-compatible and FCencouraging sluices, like (6a)-(6b) and (18b), is that the explicit version of these sentences would reveal the absence of a permission modal under 'don't care' and 'free to choose', just as Aloni's (16) does.

\subsection{Structure and isomorphy}

To begin making the argument that 'may' is at-least-semantically present in (3b) and (18a), we return to look at (5) (repeated as (19), below) in more detail. In (19b), the wh-word which occurs in isolation in a question-embedding environment (viz., under the attitude verb 'know'). Sluices like (19b) are clearly related to the full interrogative in (19c):

(19) a. Lola adopted a cat at the shelter...

b. but I don't know which.

c. but I don't know [[which cat $]_{1}$ [Lola adopted $\left.\left.t_{1}\right]\right]$ 
in which the embedded question under 'know' is overt. This is elided in the sluice:

(20) but I don't know [[which eat $]_{1}$ [Lola adopted $\left.\left.t_{\mathrm{T}}\right]\right]$

don't know...

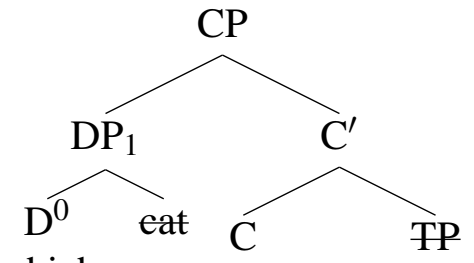

which
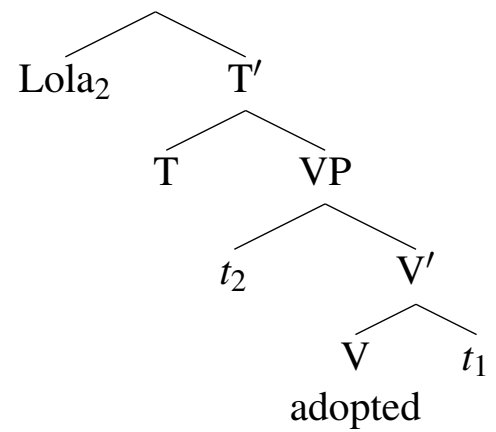

This tree shows the hallmark of $w h$-movement: a $w h$-element which originates as a complement of the verb in the sluice's antecedent — viz., the verb 'adopted' — is raised to spec-CP, leaving behind a coindexed trace.

The sluice's antecedent - (19a) - contains a correlate (here, the indefinite $a$ $c a t$ ) which corresponds to the wh-phrase in (21):

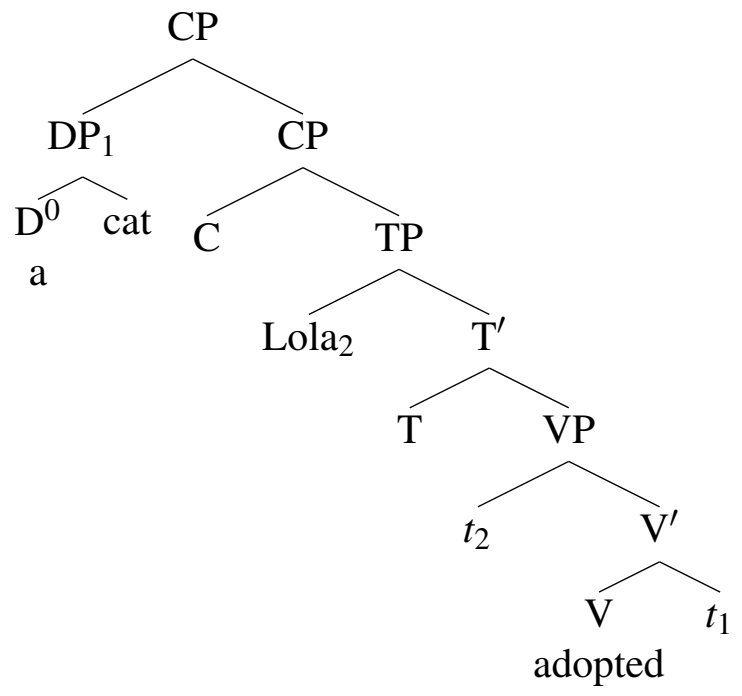


On the assumption that $a$ cat also undergoes quantifier movement to a similar position, the structure of the antecedent TP in (22) matches the structure of (21). Ellipsis - that is, non-pronunciation of the TP - is held to be licensed by this match, or isomorphism, of material. The "dangling" wh-phrase, which survives deletion where a full constituent question would otherwise be expected, is sometimes referred to as the remnant.

It is widely, though not universally, accepted that ellipsis is the non-pronunciation of fully realized syntactic structure (Ross 1969, Merchant 2001). To see why, consider Ross's argument that it would be wrong for syntactic as well as semantic reasons to take a parsimonious view of the object of the verb 'knows' in a sentence like (4), on which the direct object of the attitude verb is simply the wh-phrase. Ross argued for this by showing, for example, that $w h$-elements in sluicing show variable case inflection:

(23) Er will jemandem schmeicheln, aber sie wissen nicht wem / He wants someone.DAT flatter.INF, but they know not whom.DAT / *wen. *who.ACC.

He wants to flatter somebody, but they don't know whom. (Ross 1969: p. 253)

For English speakers sensitive to the who-whom alteration, the same point can be made by (24)-(26):

(24) John met someone, but I don't know whom/*who.

(25) Someone met John, but I don't know who/*whom.

(26) That's someone's prize possession, but I don't know whose/*who.

For philosophers and logicians primarily interested in discourses like (3), the ramifications of the argument from case-marking are worth emphasizing. Without dative case-marking on the wh-element in the German (23), for example, the sluice is not grammatical. But case marking is a local phenomenon, and the verb schmeicheln in (23) appears explicitly only in the antecedent clause- too far away to assign case to the object of wissen ('know'). Ross drew the conclusion that there is a silent token of schmeicheln, deleted under isomorphy, which assigns case to the remnant. ${ }^{6}$ Because of phenomena like case-matching, few contemporary views

6 In particular, the view Ross took from examples like (23) is now known as a "move-and-then-delete" view: wen is base-generated next to the verb schmeicheln, receives its dative case from the verb, and only then is pushed up by wh-movement to a position above the tense phrase. There, it survives deletion, while the second token of schmeicheln does not. 
Sluicing on free choice

hold that semantics or pragmatics alone can account for the acceptability and interpretation of sluices.

On the other hand, Ross's view, which requires not only fully realized syntax to be in the ellipsis site, but an exact match between this material and the syntax of the antecedent, has been challenged on the basis of other grammatical instances of sluicing where syntactic isomorphy does not appear to hold. ${ }^{7}$ The following wellknown example comes from Merchant (2001): in the antecedent, the verb is in the gerund form, but in any grammatical explicit continuation of the sentence, the verb must be in the infinitive.
a. [Decorating for the holidays is easy]...
b. if you know how.
c. * if you know how [decorating for the holidays].
d. if you know how [to decorate for the holidays]. (Merchant 2001: 22, example (30))

The right generalization seems to be that some purely syntactic features (like case) are required to match between ellipsis site and antecedent for deletion to be licensed. For others - like whether the verb is in the infinitive or gerund form - exact matching is not required. This observation makes explicit continuations less of a guide to deleted structure than they would be under an exact match view.

Importantly for our purposes, disjunction seems to present a clear stumbling block for exact matching: the key datum is that there is no syntactically isomorphic pre-sluice structure for disjunctive antecedents (Barros 2014, AnderBois 2010). To see the point, contrast the ungrammatical (28) and (30) with the grammatical (29) and (31):

(28) a. It's raining or it's snowing...

b. * I don't know which [[it's raining] or [it's snowing]].

(29) a. It's raining or it's snowing...

b. I don't know which.

(1) Er will jemandem schmeicheln, aber sie wissen nicht [[wem $\left.{ }_{1}\right]$ He wants someone.DAT flatter.INF, but they know not [[whom ${ }_{1}$.DAT] [er $t_{1}$ sehmeicheln will]]. [he $t_{1}$ flatter.INF wants]].

He wants to flatter somebody, but they don't know whom.

7 Again, Ross's view should be taken as positing an exact match only after $w h$-movement has taken place. 
(30) a. Either there's no bathroom here or it's well-hidden ...

b. * I don't know which [[there's no bathroom] or [it's well-hidden]].

(31) a. Either there's no bathroom here or it's well-hidden ...

b. I don't know which.

This is why the NCN's generalization of the pattern in Aloni's (15) was stated above in such cautious terms - in terms, that is, of what explicit versions of e.g. (18a) would reveal if it be made explicit. Because it is not generally the case that a syntactically explicit, isomorphic pre-sluice structure can be offered for disjunctive sluices, (18a) cannot be given an uncontroversial "struck-through" form, as (20) can be given for (19b). Nonetheless, we can step back from purely grammatical features and ask about the logical form of (3b) and (18a), showing that there is evidence for the presence of 'may' at LF in each. This we do in the next subsection.

\subsection{Logical form}

As emphasized by Chung, Ladusaw, and McCloskey, when a sentence with multiple quantifiers is followed up by an indefinite sluice, the licensing indefinite must be interpreted - sometimes, re-interpreted — as having wide semantic scope with respect to the other quantifiers. CLM make the argument on the basis of examples like (32):

(32) a. She always reads a book at dinnertime... we can't figure out which one.

b. Each student wrote a paper on a Mayan language... but I don't remember which one.

(Chung et al. 1995: 255)

If the isomorphy conditions for ellipsis were purely syntactic - "blind to semantics", in the helpful phrasing of Jacobson (2018) - then surface-ambiguous strings like

(33) a. She always reads a book at dinnertime (Always $<\exists) /(\exists<$ Always)

b. Each student wrote a paper on a Mayan language $(\forall<\exists) /(\exists<\forall)$

would be serviceable antecedents to sluicing regardless of which LF interpretationone which assigns wide or narrow scope to 'a book'/'a Mayan language'— the string ultimately receives. CLM's point is that this is simply not the case. Their conclusion was to recast isomorphy: sluicing, they hold, requires the copying of a semantic 
object into the ellipsis site, rather than the reproduction of a syntactic copy of the relevant Tense Phrase. ${ }^{8}$

For assessing the full case for the NCN, it is worth being precise about the limits of CLM's claim. While it is common to say that sluices on indefinites require the licensing operator to take widest LF-scope in the antecedent, this is not quite right, because multiple landing sites for both the indefinite and the wh-phrase may be available. CLM's thesis merely requires that the two are interpreted in tandem (op. cit., 256): the licensing indefinite must be interpreted as having wide scope with respect to the logical form under the remnant.

An example will be helpful in making the point. Suppose that, after hearing (34):

(34) Reginald wants to marry a millionaire.

$$
\text { (want }<\exists) /(\exists<\text { want) }
$$

we are unsure whether a de re or a de dicto desire is being ascribed to Reginald. Two different sluices - the ignorance sluice (35) and the indifference sluice (36) —on an antecedent with the surface form of (34) can push scope interpretation in one way or the other.

(35) Reginald wants to marry a millionaire... guess which.

\section{(De Re desire)}

(36) Reginald wants to marry a millionaire... he doesn't care which.

\section{(De Dicto desire)}

In (37c) and (38c), I sketch the "struck-through" completions of these matching reinterpretations of (34):

(37) a. Reginald wants to marry a millionaire ...

b. Guess which.

c. Sluice: Guess [which millionaire] $]_{1}$ [Reginald wants PRO to marry $t_{\mathrm{T}}$ ] (Re)interpreted antecedent: $\left[[\exists x \text { millionaire } x]_{1}\right.$ Reginald wants PRO to marry $t_{1}$ ] Indefinite has wide scope in the antecedent

(38) a. Reginald wants to marry a millionaire ...

b. He doesn't care which.

c. Sluice: He doesn't care [which millionaire $]_{1}$ [PRO to marry $\left.t_{\mathrm{T}}\right]$ (Re)interpreted antecedent: [Reginald wants $\left[[\exists x \text { millionaire } x]_{1} \mathrm{PRO}\right.$ to marry $\left.t_{1}\right]$ Indefinite has narrow scope in the antecedent

8 The view is now known as "LF copying". 
In the contrast between (38c) and (37c), we see CLM's qualified wide-scope thesis at work. (38) is not interpreted as a statement of Reginald's indifference about which millionaire he wants to marry. ${ }^{9}$ Hence, the existential correlate $\ulcorner\exists x$ millionaire $x\urcorner$ is not (re-)interpreted as taking widest scope in the antecedent. It is, however, (re)interpreted as taking scope over the material that is recycled in the sluice (which is subsentential and does not include the scope-bearing operator 'want'). To put the point more neutrally - in a way that does not literally read the struck-through material in (37c) and (38c) as syntactically present - the meaning of the deleted tense phrases are interpreted $a s$ if the wh-phrase took scope parallel to the interpreted scope of the existential. ${ }^{10}$ In each case, structural disambiguation of the antecedent is being driven by the meaning of the verb ('guess' vs. '(don't) care'). The absence of 'want' in (38c), as well as its presence in (37c), is analogous to the absence of 'may' in Aloni's (16), and its presence in her (15).

\subsection{Free choice antecedents}

We now return to Free Choice antecedents, including the contrasting sluices $(3 \mathrm{~b})$ and $(39 b)$ :

(3) a. You may have coffee or tea ...

b. I don't know which.

a. You may have coffee or tea...

b. I don't care which.

What we wanted to investigate was whether 'may' is present in these sluices; a clue was provided by the observation that while the ignorance sluice (3b) apparently cancels the free choice effect, the indifference sluice (39b) does not. My suggestion is that we apply CLM's hypothesis about parallel scope. Recall the contrast between

9 While not impossible, this would be a bizarre, second-order mental state to be in. For example: Reginald can swallow one of $n$ pills, each of which will induce in him a different de re desire to marry millionaire $x_{i}$ for $1 \leq i \leq n$. If, even though Reginald wants to swallow a pill - since he cares to be in a de re state of wanting to marry some particular millionaire - he is indifferent to which such state he cares to be in, and hence which such pill he will take, then he might be in the state corresponding to $\ulcorner\exists x$ millionaire $x\urcorner$ taking widest scope in the antecedent of (38).

10 The careful reader will note that like (28b) and (30b), (38c) in fact cannot be read grammatically as written without the strikethrough: it would be

(38) d. Sluice: * He doesn't care which millionaire to marry.

Hence (38c) provides another apparent counterexample to the "exact syntactic match" condition on sluicing. Thanks here to Gary Thoms. 
(37) and (38): these sluices trigger incompatible reinterpretations of their shared antecedent. Moreover, while a sluice-licensing existential need not take widest scope in the antecedent to be interpretable, it must take wide scope with respect to the the material present in the sluice. We can apply the same pattern to (3b) and (39b). Disjunction will take wide scope with respect to the modal just in case the "material" - whether syntactic or merely interpreted - beneath 'which' in the sluice (39b) includes the modal 'may'. In the style of (38), the deleted material in (39b) is:

(40) I don't care [which өne $]_{1}\left[\right.$ you have $\left.t_{T}\right]$ (FC-compatible sluice)

while, in the style of (37), the deleted material in (3b) is:

\section{(41) I don't know [which one $]_{1}$ [you may have $t_{1}$ ]} (FC-incompatible sluice)

The pattern we find again parallels the contrast between Aloni's (15)-(16). In (40), the speaker expresses indifference concerning worldly facts. But in (41), the speaker expresses ignorance concerning modal facts. The latter, and not the former, is in Moorean tension with a free choice reading of the antecedent. This offers an explanation for why the latter, but not the former, would be parsed in a way which does not give rise to Free Choice in the first place.

As noted in Section 2, the NCN extends this analysis to the general case, including Free Choice antecedents like (18) (repeated):

(18) You may [[drink tea] or [eat cake]]...

a. I don't know which.

b. I don't care which.

where there is no verb like 'take' or 'eat' in common between the disjuncts. In keeping with my strictures for these examples, I have not provided a "struck-through" parse for the sluices (18a) and (18b). Because an analogy with explicit form is bound to fail, as in (28b) and (30b), the content of the relevant completion is too controversial. Nonetheless, the moral from (37)-(38) and (40)-(41) generalizes. Whatever the copied material in these sluices is - and whether the right interpretation of it is as a fully realized syntactic object, a logical form, or something with the features of both - there is good reason to think that (18a) includes 'may' at LF, while (18b) does not. By CLM's parallel LF scope generalization, 'or' is thus interpreted as scoping over the modal when (18) is followed by the ignorance sluice (18a), and under it when (18) is followed by the indifference sluice (18b). 


\section{Conjunctive sluices}

In this section I present some additional data, from non-existential sluice constructions, for the picture of Free Choice sketched above. 'else'-sluices, such as (42), can take conjunctions as antecedents (Merchant 2001: Section 4.2.2):

(42) a. William and Tom came to the bar...

b. But I don't know who else/*who.

While it would be Moore-paradoxical for a speaker to say that William came to the bar and that Tom came to the bar and that she (the speaker) does not know who came to the bar, the addition of 'else' renders (42) semantically and pragmatically acceptable.

The additional datum I want to consider is that Free Choice sentences license both 'else' - and 'else'-free ignorance sluices.

(43) You may have coffee or tea, but I don't know which.

(44) You may have coffee or tea, and I don't know what else.

Strikingly, although it is an ignorance sluice, the sluice in (44) does not cancel Free Choice; in fact, like the indifference and encouragement sluices in (6a) and (6b), it appears to presuppose choice. The question is whether the overall picture of FC sluices sketched above - narrow-scope Free Choice 'or', wide-scope structural reinterpretation in (3b), and LF parallelism - can shed light on this.

It seems that it can. The key is that the addition of 'else' ameliorates, as it does in (42), the threat of Moorean tension with a second available parse of the Free Choice antecedent. Hence that second interpretation again becomes available when 'else' is added.

For a comparison, consider (46)-(47), which share a scopally ambiguous antecedent ('Pontius Pilate refused to pardon Christ or Barabbas') with disjunction and negation. Like free choice antecedents, this antecedent supports both 'else'and 'else'-free ignorance sluices.

(45) Pontius Pilate refused to pardon Christ or Barabbas.

$(\neg<\exists) /(\exists<\neg)$

(46) Pontius Pilate refused to pardon Christ or Barabbas; I don't remember which.

(47) Pontius Pilate refused to pardon Christ or Barabbas, and I don't know who else. $^{11}$

11 It can be helpful to add a pitch accent on 'or' for (47). Thanks here to Chris Barker. 
While both types of ignorance sluice are supported, however, the 'else'-sluice, (47), favors a different parse of the antecedent than the 'else'-free (46) favors. In particular, it favors the interpretation $\neg($ c or $b) \equiv \neg c \wedge \neg b$, on which (47) and the conjunctive antecedent in (48) are equivalent:

(48) Pontius Pilate refused to pardon Christ and Pontius Pilate refused to pardon Barabbas, and I don't know who else [Pontius Pilate refused to pardon $t$ ].

As in the case of (18), the syntactic structure of (42) and (48) is controversial. Since 'and' does not undergo quantifier movement, it is mysterious how there would come to be a trace in the struck-through material in (48) for the wh-element 'who else' to bind.

Nonetheless, the interpretive facts are clear: even though both the 'else'-sluice (47) and the 'else'-free (46) are ignorance sluices, they differ with respect to the structural interpretations they favor for their shared antecedent. The 'else'-sluice (47) favors the parse $(\neg(\phi$ or $\psi))$, because this is semantically equivalent to the conjunction $(\neg \phi \wedge \neg \psi)$. By contrast, the 'else'-free sluice (46) favors the parse $(\neg \phi$ or $\neg \psi)$, in which disjunction takes wide scope. Returning to free choice: on the picture offered here, the 'else'-sluice (44), unlike the 'else'-free sluice (43), favors the parse $(\diamond(\phi$ or $\psi))$ because this is the parse which semantically entails — via free choice - the conjunction $(\diamond \phi \wedge \diamond \psi)$. This is why the subsequent sluice can presuppose, rather than be felt to cancel, FC.

\begin{tabular}{llll}
\hline$\neg(\phi$ or $\phi)$ & $\neg \phi$ or $\neg \psi$ & $\nabla(\phi$ or $\psi)$ & $\checkmark \phi$ or $\diamond \psi$ \\
$\vDash_{\text {DeMorgan } \neg \phi \wedge \neg \psi}$ & & $\vDash_{\text {Free Choice }} \nabla \phi \wedge \diamond \psi$ & \\
\hline 'or' narrow: conjunctive & 'or' wide: disjunctive & 'or' narrow: conjunctive & 'or' wide: disjunctive \\
interpretation & interpretation & interpretation & interpretation \\
goes with 'else'- & goes with 'else'-free & goes with 'else' & goes with 'else'-free \\
ignorance sluice (47) & ignorance sluice (46) & ignorance sluice (44) & ignorance sluice (43)
\end{tabular}

Table 1 'else'-sluice data.

The data from (43)-(47), summarized in Table 1, add to our understanding of the conditions under which the apparent cancellation effect obtains for FC. It was already widely known that not all sluices on Free Choice antecedents give rise to apparent cancellation; only ignorance ones do. To this, we can add that not even all ignorance sluices on FC antecedents give rise to apparent cancellation. Only 'else'-free ignorance sluices like (3b) do. The view from the NCN suggests that this relies on the following delicate fact: in disjunctive ignorance sluices without 'else', 
disjunction is naturally interpreted as the locus of ignorance - therefore, disjunction scopes wide in the antecedents of such sluices. Without anything like 'else' to change the relevant pragmatic context, this precludes structural interpretations of the antecedent which are in Moorean tension with such ignorance.

\section{Conclusion}

I've explored the implications of Tense Phrase ellipsis — that is, sluicing — for the Free Choice effect. In particular, I argued that the time-honored 'I don't know which'-riders on Free Choice sentences, traditionally taken to confine the effect to the farther side of the semantics-pragmatics divide, do not in fact show any such thing. Indeed, the view from sluicing suggests that, when the scope of 'or' is narrower than the scope of the modal, Free Choice is not cancellable, and hence patterns semantically with indefinite "free choice items" (FCIs) like the English any.

Beyond the lexical considerations advanced in Section 2, I made the argument by appealing to two highlights from the indefinite-focused sluicing literature. The first, following Ross and Merchant, was simply that sluicing is constrained by form. The second, following CLM, drilled down into the (at least partially) semantic nature of that constraint: to wit, that the licensing operator outscopes anything semantically present in the sluice. Finally, I discussed 'else'-sluices and their ability to target conjunctive interpretations of antecedents featuring 'or'.

\section{References}

Aloni, Maria. 2007. Free choice, modals, and imperatives. Natural Language Semantics 15. 65-94. https://doi.org/10.1007/s11050-007-9010-2.

Aloni, Maria. 2019. FC disjunction in state-based semantics. Ms., ILLC, University of Amsterdam. maloni.humanities.uva.nl/resources/draft-nyu(revised).pdf.

AnderBois, Scott. 2010. Sluicing as anaphora to issues. In Proceedings of SALT 20, https://doi.org/10.3765/salt.v20i0.2574.

Barros, Matthew. 2014. Sluicing and identity in ellipsis: Rutgers University dissertation.

Chierchia, Gennaro. 2006. Broaden your views: Implicatures of domain widening and the 'logicality' of language. Linguistic Inquiry 37(4). https://doi.org/10. 1162/ling.2006.37.4.535.

Chung, Sandra, William Ladusaw \& James McCloskey. 1995. Sluicing and logical form. Natural Language Semantics 3. 239-282. https://doi.org//10.1007/ BF01248819. 
Sluicing on free choice

Dawson, Virginia. 2019. Lexicalizing disjunction scope. In Proceedings of the linguistics society of America, vol. 4, 1-13. https://doi.org/10.3765/plsa.v4i1. 4520.

Dayal, Veneeta. 2004. The universal force of free choice Any. Linguistic Variation Yearbook 4. 5-40. https://doi.org/10.1075/livy.4.02day.

Grice, H. Paul. 1978. Further notes on logic \& conversation. In Grice (1991), Harvard University Press.

Grice, H. Paul. 1991. Studies in the way of words. Harvard University Press.

Hawke, Peter \& Shane Steinert-Threlkeld. 2015. Informational dynamics of 'might' assertions. In W. vander Hoek, W. Holliday \& W. Wang (eds.), Logic, rationality, and interaction, 143-155.

Hawke, Peter \& Shane Steinert-Threlkeld. 2016. Informational dynamics of epistemic possibility modals. Synthese 195(10). 4309-4342. https://doi.org/10. 1007/s 1122.

Jacobson, Pauline. 2018. The (persistent) myth of silent linguistic material. Handout from talk at PhLiP Conference, Tarrytown, NY, November 2018. Based in part on joint work with Scott AnderBois.

Kadmon, Nirit \& Fred Landman. 1993. Any. Linguistics and Philosophy 16(4). 353-422. https://doi.org/10.1007/BF00985272.

Kamp, Hans. 1973. Free choice permission. Proceedings of the Aristotelian Society, New Series 74. 57-74.

Kamp, Hans. 1978. Semantics versus pragmatics. In F. Guenthner \& S.J. Schmidt (eds.), Formal semantics and pragmatics for natural languages, Reidel, Dordrecht.

Merchant, Jason. 2001. The syntax of silence. Oxford University Press.

Meyer, Marie-Christine. t.a. An apple or a pear: Free choice disjunction. To appear in Companion to Semantics (Wiley). semanticsarchive.net/Archive/ TNjNDM2M/meyer_fc_2015.pdf.

Ross, John Robert. 1969. Guess who? In R. Binnick, A. Davidson, G.M. Green \& J. L. Morgan (eds.), The sixth annual meeting of the northeastern linguistics society, 252-286.

Sæbø, Kjell Johan. 2004. Natural language corpus semantics: The free choice controversy. Nordic Journal of Linguistics 27(2). 197-218. https://doi.org/10.1017/ S0332586504001210.

Simons, Mandy. 2005. Dividing things up: The semantics of $\mathrm{Or}$ and the modal/Or interaction. Natural Language Semantics 13. 271-316. https://doi.org/10.1007/ s11050-004-2900-7.

Starr, Will. 2016. Expressing permission. In Mary Moroney, Carol-Rose Little, Jacob Collard \& Dan Burgdorf (eds.), Proceedings of SALT 26, 325-349. https: //doi.org/10.3765/salt.v26i0.3832. 


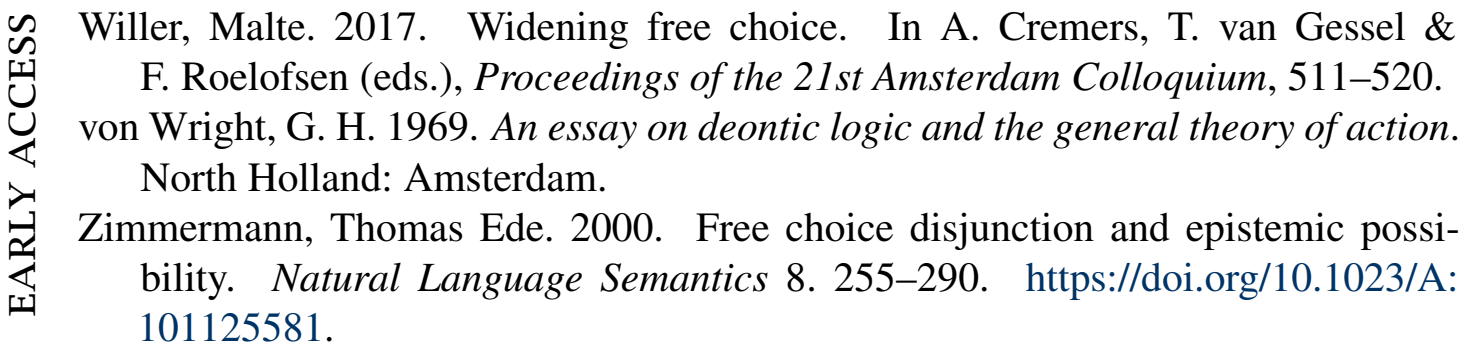

Melissa Fusco

Department of Philosophy

Columbia University

New York, NY 10027

mf3095@columbia.edu 